\title{
SURFACE-ENHANCED FLUORESCENCE AND RAMAN SCATTERING STUDY OF ANTITUMORAL DRUG HYPERICIN: AN EFFECT OF AGGREGATION AND SELF-SPACING DEPENDING ON pH
}

\author{
Gejza Lajos $^{1}$, D. Jancura ${ }^{1}$, P. Miskovsky ${ }^{1,3}$, J. V. García-Ramos ${ }^{2}$, S. Sanchez-Cortes ${ }^{2}$ \\ 1 Division of Biophysics, Safarik University, Jesenna 5, 04154 Kosice, Slovakia \\ 2 Instituto de Estructura de la Materia, CSIC, Serrano 121, 28006 Madrid, Spain \\ 3 International Laser Centre, Ilkovicova 3, 81219 Bratislava, Slovakia \\ gejza.lajos@upjs.sk
}

Surface-enhanced Raman scattering (SERS) represented a great advance in the field of Raman spectroscopy. SERS is based on the huge enhancement of Raman emission of certain molecules when they are placed in the proximities of certain rough metal surfaces. $(1,2)$ This technique can be successfully applied in the study of poor soluble compounds in water, since very low concentrations are required. The main advantage of the SERS is the fluorescence quenching occurring on the metal surface (3). The fluorescence quenching occurring on metal nanoparticles (NPs) is attributed to charge-transfer phenomena taking place between the adsorbate and the metal. However, at a proper distance from the surface (more than $50 \AA$ ) the emission of fluorophore can be enhanced by metal surface, and this phenomenon is called SEF (Surface-enhanced fluorescence) or MEF (metal-enhanced fluorescence)(4). The fluorescence emission of fluorophores is markedly enhanced at distances between 70 and $100 \AA$ (4). If the distance from the surface is not too far, a combined SERS+SEF spectrum can be registered, thus providing information from the vibrational and electronic processes occurring in the adsorbed species. In order to place the fluorophore at a proper distance from the metal one must functionalize the metal surface with a spacer. This was accomplished by covering the NPs with spacers such as fatty acids $(5,6)$, or proteins $(7)$. In this work we demonstrate that intense SEF spectra can be obtained by self-spacing when using fluorophores able to aggregate at certain conditions. This is the case of many anthraquinone antitumoral drugs such as hypericin $(3,8)$. In this case, intense SERS and SEF spectra can be obtained and can be used to understand the aggregation processes taking place in these important molecules.

In this work we show the SEF and SERS combined spectra of HYP and the dependence on the $\mathrm{pH}$, when adsorbed on colloidal silver and aqeuous solution at different $\mathrm{pH}$. This is also the first step in the application of SEF-SERS study of anthraquinone drugs interacting with biomolecules.

\section{References:}

[1] Moskovits, M. Rev. Mod. Phys, 57, 1985,783

[2] Wokaun, A. Mol. phys, 56, 1985, 1

[3] D. Jancura, S. Sanchez-Cortes, E. Kočišová, A. Tinti, P. Miškovský and A. Bertoluzza; Biospectroscopy Vol. 1, No. 4, 1995, 265-275

[4] Lakowicz, JR, Geddes, CD, Gryczynski, I, et al. J. Fluorescence 14 (4): 2004, 425 441 ,

[5] C. J. L. Constantino and R. F. Aroca; J. Raman Spectrosc. 31, 2000, 887-890

[6] C.J.L. Constantino, R.F. Aroca, C.R. Mendonc, S.V. Mello D.T. Balogh, O.N. Oliveira Jr.; Spectrochimica Acta Part A 572001 281-289

[7] Badri P. Maliwal, Joanna Malicka, Ignacy Gryczynski, Zygmunt Gryczynski, Joseph R. Lakowicz; Biopolymers (Biospectroscopy), Vol. 70, 2003, 585-594

[8] P. Miškovský, L. Chinsky, G. V. Wheeler and P. Y. Turpin; Journal of Biomolecular Structure and Dynamics Vol. 13, No. 3, 1995, 547-552, 

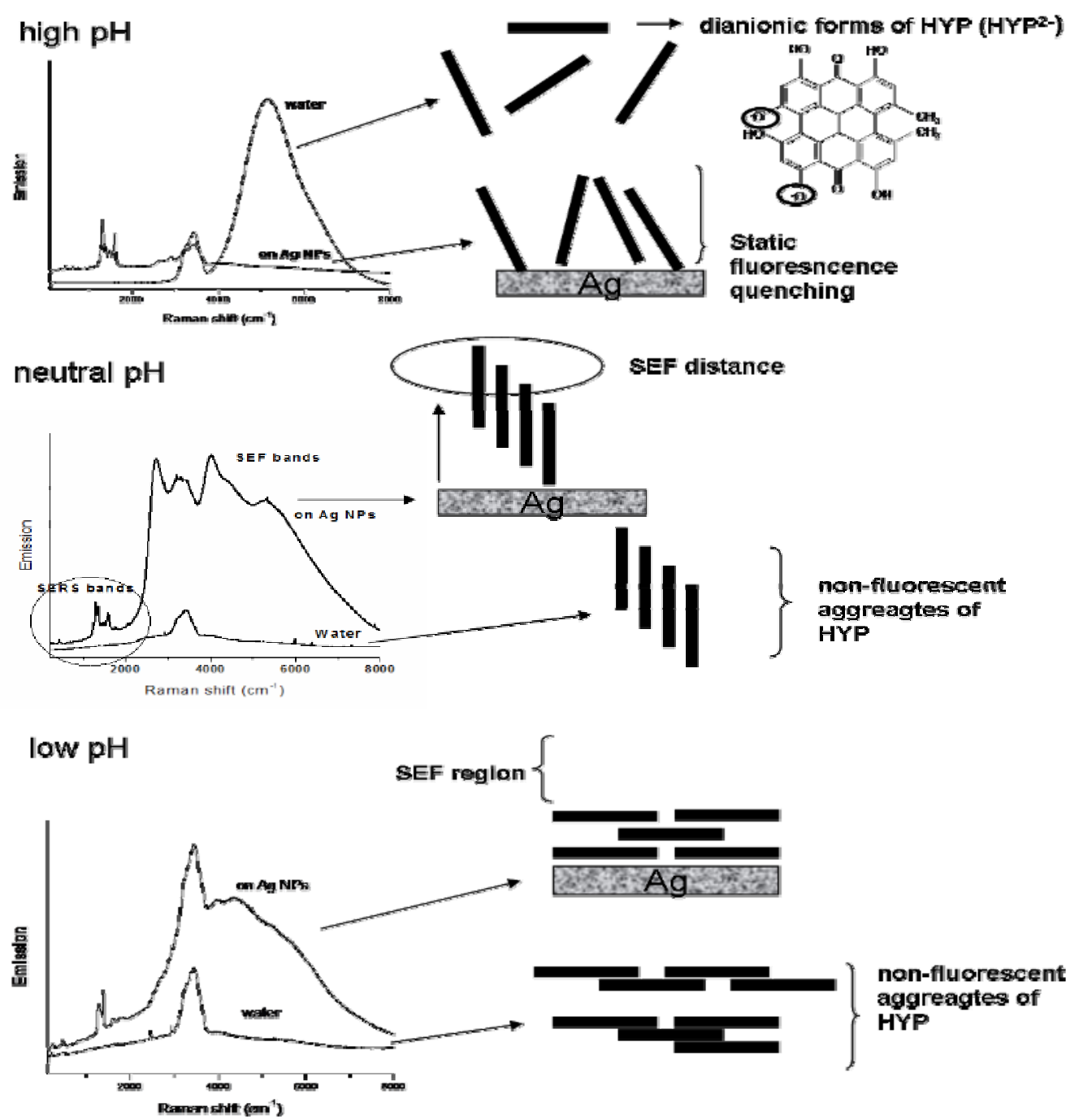

Figure: Schematic explanation of state of Hyp in water and colloid at different $\mathrm{pH}$ 